\title{
Heat Transfer Enhancement: A Review of Ongoing Issues
}

\author{
Ranjan Kumar, Shreya Agarwal
}

\begin{abstract}
In this paper, we discuss about various methods adopted by researchers around the world for heat transfer enhancement. Three major categories of heat transfer enhancement techniques viz. annihilation of thermal boundary layer, employment of magnetohydrodynamics flow and enhancement of critical heat flux during boiling are studied in brief. We also present about the advantages as well as drawbacks of each one of them. There are various field of application in the real world where these methods can be utilized, but each has its own limitations which we discuss in the current work. Through this work we put forward a well comprehension of the ongoing issues in heat transfer, thermal management and energy savings which are always the centre of attraction for the researchers from wide-ranging field in engineering.
\end{abstract}

Index Terms-heat transfer enhancement, boiling, thermal boundary layer.

\section{INTRODUCTION}

Heat transfer enhancement has become a vital subject of study in the field of engineering. Along with the development of newer technologies ranging from nanoscale devices to automobiles as well as big satellites, efficient management of energy by the application of proper heat transfer is imperative. In the past century and now many researchers have worked in the field of heat transfer enhancement. Passive method has been implemented experimentally for bulk fluid flow [1-9]. Also, computational fluid dynamic simulations and experiments in mixed convection using magnetic field with varying sources and methods of parametric variation to attain efficient heat transfer has also been investigated to a great extent [10-18]. In addition to the heat transfer at normal temperature, researchers now-a-days are also equally interested to study heat transfer enhancement during boiling at temperature $T>100^{\circ} \mathrm{C}$; the method typically known as enhancing the critical heat flux (CHF) by employing different kinds of surface modification [19-24]. In this paper, we discuss about the different kinds of heat transfer enhancement techniques utilized, the method of their application in the practical world and their limitations. We present a comprehensive understanding of these techniques and suggest the further research and development associated with them for better thermal management and energy savings in future.

Ranjan Kumar, Department of Mechanical Engineering, Bangalore Institute of Technology, Bangalore, India.

Shreya Agarwal, Department of Mechanical Engineering, Bangalore Institute of Technology, Bangalore, India

\section{HEAT TRANSFER MECHANISMS}

\section{A. Conduction Heat Transfer}

Thermal conductivity $k$ of a material (solid or fluid) is the major role playing factor for conduction heat transfer. Thus, for an application associated with enhancing heat transfer using conduction, design of devices based on $k$ is sufficient.

\section{B. Convection Heat Transfer}

When the particle of fluid (gas or liquid) move with certain velocity and carry heat energy with them, it's called convection. Although in general convection just deals with the motion of fluid and properties of fluid, in the field of heat transfer enhancement, convection is of crucial importance. Most of the researches carried out take the advantage of enhancing the convection heat transfer.

\section{Radiation Heat Transfer}

It is the transfer of heat in the form of electromagnetic radiations. This kind of heat transfer is more applicable in space so lesser discussed in the literature of heat transfer enhancement techniques.

\section{Boiling}

Boiling is the vigorous vaporization of liquid which occurs at temperature at the boiling point of that liquid. Basically, there are two kinds of boiling: (i) Nucleate boiling and (ii) Critical heat flux boiling. In nucleate boiling, bubbles form at the heated surface and depart continuously. When the surface is heated much higher than the saturated temperature i.e. above a critical temperature, a thin film of vapor forms on the surface and that phenomenon is called critical heat flux boiling. In boiling, CHF indicates a thermal limit to the process of heat transfer during boiling where, the surface is covered with a thin film of vapor. Vapor layer being bad conductor of heat, the heat transfer from the heated surface to the bulk liquid is restricted to this limit. Thus, one major objective in heat transfer enhancement for boiling is to shift this limit of CHF to higher value so that more heat can be extracted from the surface ultimately enhancing the thermal efficiency.

\section{HEAT TRANSFER ENHANCEMENT}

In this paper, we have discussed three major classes of heat transfer enhancement techniques: (i) Passive method of 


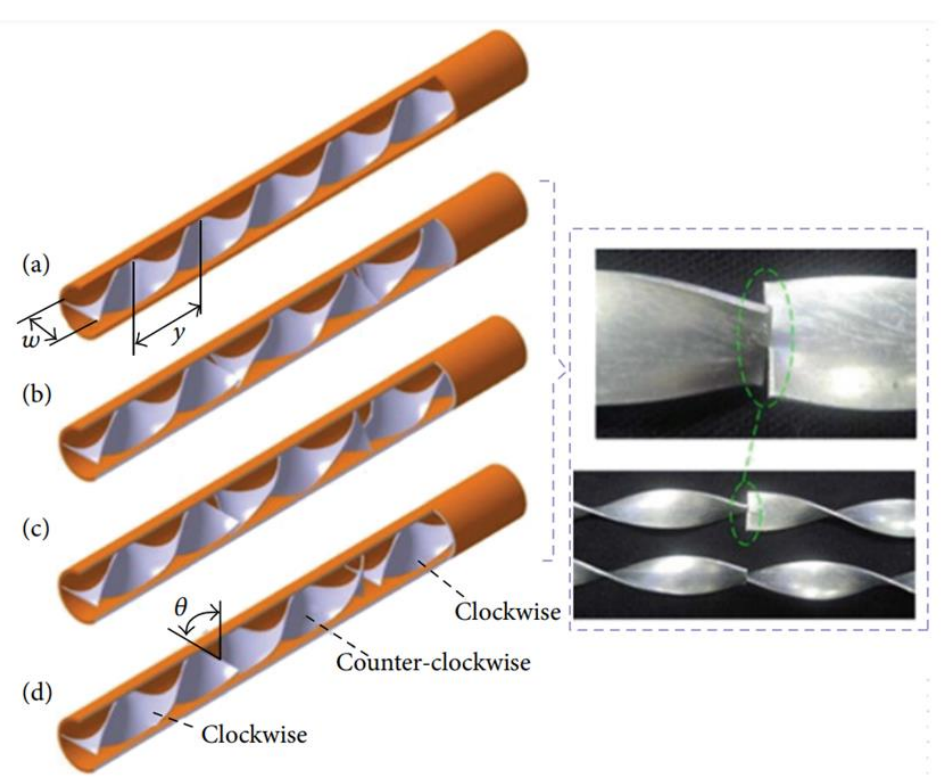

(e)
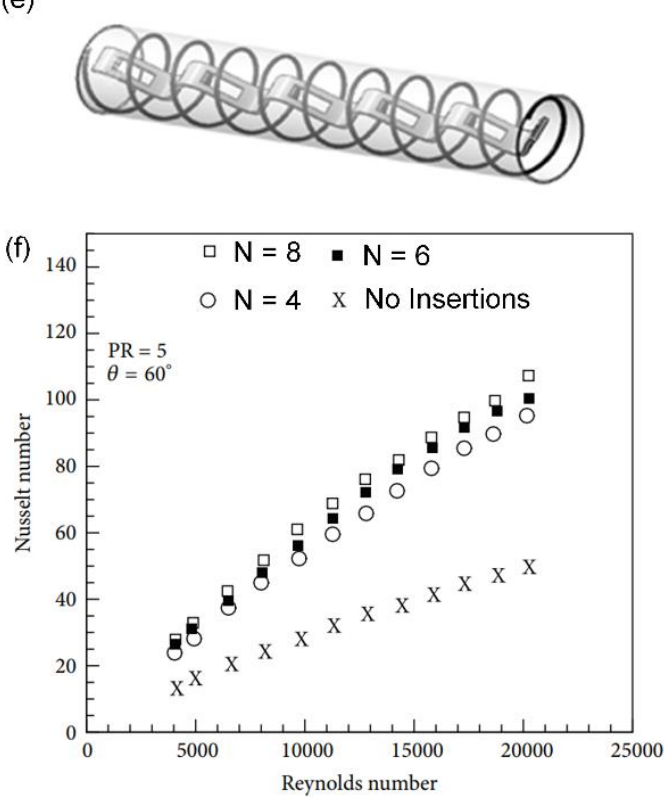

Fig. 1 (a-d) Sketch of clockwise and counter-clockwise twisted tape used as insertions for heat transfer enhancement [7]. (e) Combined wire coil and wavy strip used for insertion [8]. (f) Variation of Nusselt number with Reynolds number for different number of blades $N$ in insertions used at given pitch ratio $P R$ and blade angle $\theta$ [9]

convection heat transfer enhancement by annihilation of thermal boundary layer (ii) Convection heat transfer enhancement using magnetohydrodynamics (MHD) flow (iii) Phase change heat transfer enhancement via $\mathrm{CHF}$ enhancement.

\section{A. Annihilation of thermal boundary layer}

In the convection heat transfer mechanism, formation of thermal boundary layer is a major hindrance. Thus, by using various techniques of delaying and/or eradicating the thermal boundary layer, convection heat transfer can be enhanced. This can be done by using an artificial roughness on the walls through which heat transfer occurs. Artificial roughness can be gained by using corrugated tubes $[1,3,5]$, dimpled tubes [1] or wire coils [3]. Additionally, wall-shear and temperature-gradients near the walls can also be adjusted using inserts like twisted tape [2, 4]. The modified shear and temperature-gradient will result into augmented heat transfer due to convection on such walls.

In such kind of analysis, where one is interested to enhance convection heat transfer coefficient, Nusselt number is calculated for the flow inside a tube. The calculation directly reveals the estimation of heat transfer enhancement due to convection as carried out by Agarwal and Rao [6] and Deb and Poudel [8].

Fig. 1(a-d) depict different kinds of twisted tapes arrangement inside the heat transferring tubes [7] while fig. 1(e) illustrate a combined wire coil and wavy strip used as insertion for better enhancement in convection heat transfer [8]. The plot in fig. 1(f) shows the variation of Nusselt number with Reynolds number and clearly indicates that there is enhanced heat transfer by the use of insertions of different shapes and numbers [9].

This technique has long been used and shows satisfactory performance in experiments. However, the actual amount of heat transfer enhancement achieved using this technique is not so much. There are limitations of different designs of insertions for different kinds of flow as well. In practice when the flow is turbulent and the heat transfer surface is uneven, the design of insertions will be complicated.

\section{B. Heat transfer enhancement using MHD convection}

Heat transfer in mixed convection flows has a great importance in the field of engineering applications like electronic cooling, heat exchanger, solar ponds, nuclear power plants, etc. Various experimental as well as computational researches have been performed in order to comprehend the hydromagnetic effect in convection heat transfer. Chamkha [10] studied the hydromagnetic convection during unsteady laminar flow in a vertical lid-driven square cavity where an internal heat generation as well as absorption effects were compared to understand the aiding as well as opposing flows.

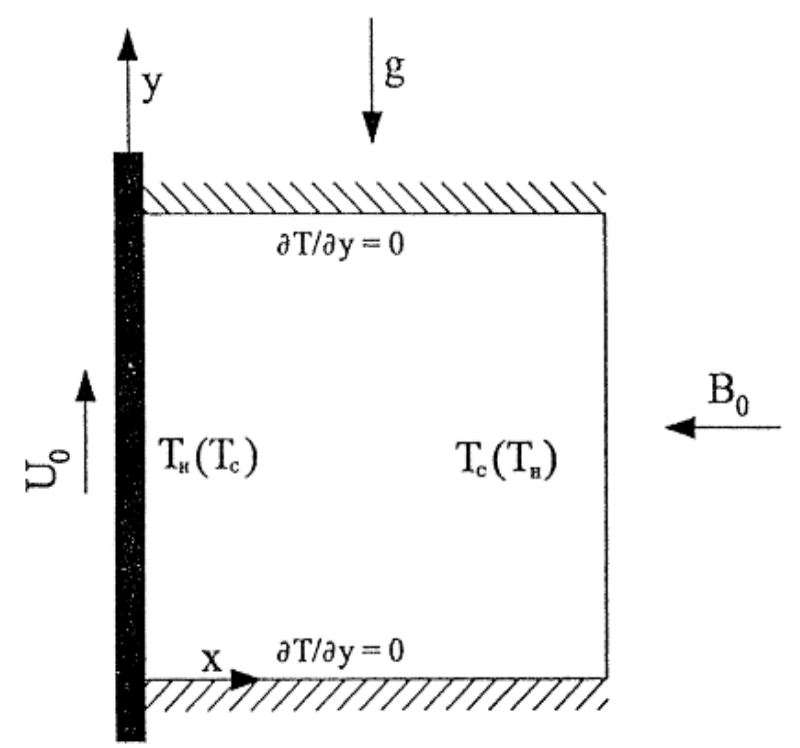

Fig. 2 Schematic of square lid-driven cavity with lid velocity $\left(\mathrm{U}_{\mathrm{o}}\right)$ and magnetic field $\left(\mathrm{B}_{\mathrm{o}}\right)$ to study MHD flow [10]. 
(a)

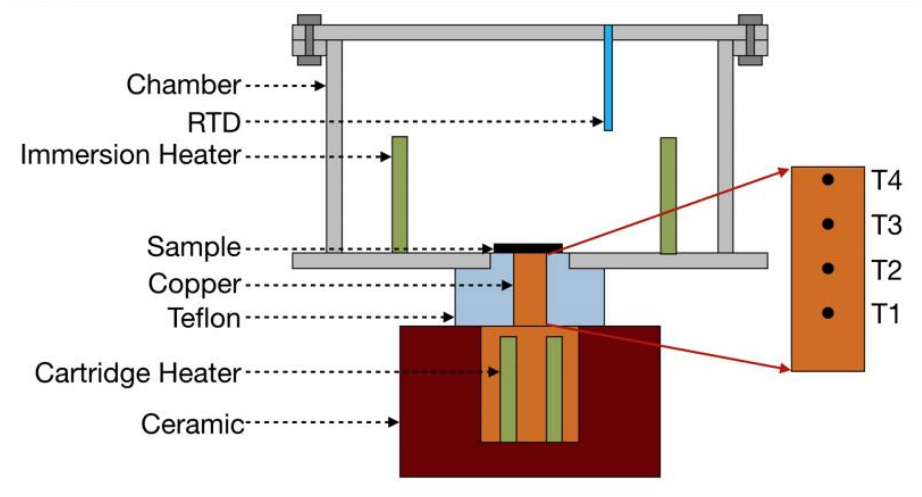

(b)

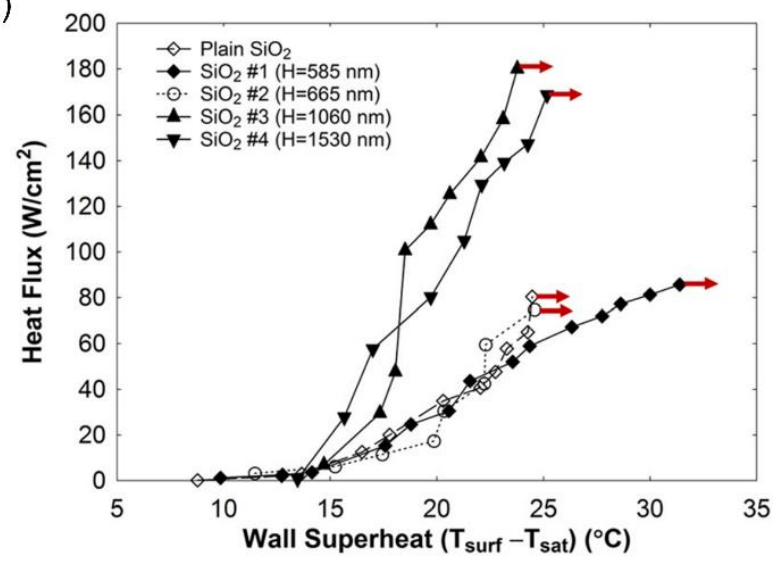

Fig. 3 (a) Experimental setup used for studying pool boiling with porous structure (sample) as heat transfer surface heated using copper rod and water enclosed in chamber [21] (b) Heat flux versus wall super heat showing the higher CHF attained by using micro and nano meters scale structures for heat transfer during phase change at boiling [23]

Generally, a lid-driven cavity as shown in fig. $2[10]$ is used to study the phenomenon. In a typical lid-driven square cavity simulation (fig. 2), two opposite walls are kept at certain fixed temperature (one higher $T_{H}$ and other lower $T_{C}$ ). And, the other two walls are kept insulated with no heat flux $(\partial T / \partial y=0)$. Magnetic field of strength $B_{o}$ is applied across the cavity in a particular direction and one of the lids is driven tangentially with velocity $U_{o}$. Study of fluid flow and heat transfer is carried out in this fashion.

Further investigations in this field include one by Cheng and Liu [11] who explained the effect of temperature gradient on the fluid flow and heat transfer for two cases: one assisting buoyancy second opposing buoyancy. In addition to the fluid flow and heat transfer inside a cavity, people also performed exploration by inserting obstacle into the cavity with an aim of enhancing heat transfer. The insertion of obstacle inside the cavity turned out to be an important enhancer of heat transfer in a mixed flow as done by Khanafer and Aithal [12], Chatterjee et al. [13], Ray and Chatterjee [14] and Deb et al. $[17,18]$. Nevertheless, the study of such kind of heat transfer enhancement has always been with and around one common component: lid-driven cavity. The effect of the direction of lid in the lid-driven cavity on the $M H D$ convection was also studied by Al-Salem et al. [15] and Ismael et al. [16].

The major lead of using lid-driven cavity for comprehending the effect of MHD flow in heat transfer enhancement are: we can directly visualize the flow of liquid inside the cavity through streamlines, the parametric study of the flow and heat transfer is easy to conduct and the heat transfer factors like Nusselt number $\mathrm{N} u$, Richardson number $R i$, etc. can be easily extracted during the flow. In this way, study of heat transfer enhancement in MHD flow has become one important topic in discussion. However, magnetic field and its effect in heat transfer being lesser understood aspect of physics, it should be renewed a lot before applying this technique directly in the application field.

\section{CHF enhancement during boiling}

Very high amount of heat transfer during phase change as compared to the heat transfer due to sensible heating is the major motivation of large number of research being carried out in the field of CHF enhancement during boiling. Ever since the beginning of this century people have tried different ways to enhance heat transfer by shifting CHF to higher values. More importantly, almost all of the techniques converge to a common point: surface modification. Hydrophilic substrate or walls have superior heat transfer properties in terms of CHF [20]. Due to which, CHF enhancement during boiling is studied in depth by many researchers around the world [19-24].

One common way to enhance CHF is to create a porous structure. The porous structures might be of micro or nano meters scale like: micropillars [19], nanowires [20], nanochannels [21, 22], etc. By creating a porous structure, liquid water during boiling attaches with the substrate for a longer period of time and thus keeps on replacing the space of evaporated liquid. This way critical limit for boiling is shifted and CHF is enhanced. Typically boiling is performed on a fixed water tank with heater attached to the porous structure as shown in fig. 3(a) [21]. This kind of boiling is called pool boiling where the bulk liquid is not in motion (unlike flow boiling). The heating rod is supplied with power and the heat flux is continuously increased. Heat flux is calculated and recorded instantaneous and once the CHF is reached, heat flux decreases due to the vapor layer covering the entire heat transfer surface of the porous structure (sample) [21].

CHF enhancement in pool boiling has been a successful technique to acquire high heat transfer rates so far. Fig. 3(b) shows that heat flux enhancement (CHF enhancement) of $\sim 180 \%$ was attained by utilizing proper micro and nano meter structured surface [23]. Reference [24] was able to enhance CHF by $400 \%$ in pool boiling by employing a porous structures of nanowires.

One of the most advantageous aspect of this kind of heat transfer enhancement is that, the amount of heat transfer during phase change is very high and the enhancement achieved can also be in 100s of percentage as compared to the normal surface. This means, this sort of enhancement has the major lead in terms of thermal management and energy savings as compared to any other kind of enhancement. Nevertheless, in practical world, when we try to employ such kind of heat transfer enhancement in nuclear, aeronautical, automobile and electronic industries [25] as well as in regard with the application in space, the technique should be made robust and cheaper. Most of the micro and nano meters scale surface modification techniques discussed above are not so robust and the experimental setup as used by them to attain CHF enhancement cannot be directly implemented in such 
ground based industries or in space. Also, if we try to utilize these techniques by replacing all the convenient heat transfer surfaces in all the power plants in this world, it needs a lot of budget since those porous structures are manufactured using complex and expensive nanotechnology. The nanotechnology and manufacturing facilities are also not accessible to all the people around the world.

\section{CONCLUSIONS}

In this paper we discussed about the various ongoing work in the field of heat transfer enhancement. Three major categories of heat transfer enhancement were studied: (i) Passive method of convection heat transfer enhancement by annihilation of thermal boundary layer (ii) Convection heat transfer enhancement using magnetohydrodynamics (MHD) flow (iii) Phase change heat transfer enhancement via $\mathrm{CHF}$ enhancement. Annihilation of thermal boundary layer is found to be good in practice but the level of enhancement is not so great. The second method through MHD flow is also good for investigation of parameters associated; nevertheless the actual practical application using MHD flow is yet to be revealed. The third type of heat transfer enhancement by employing phase change and CHF enhancement is very effective and can be applied in industries to gain a large amount of heat transfer enhancement. Still there are issues with the robustness of the porous structures and expenses of manufacturing such structures to employ them in $\mathrm{CHF}$ enhancement. Finally, we are able to elaborate the comprehensive study of ongoing researches in the field of heat transfer enhancement and suggest the idea regarding the further research in related field.

\section{REFERENCES}

[1] Solano, J. P., García, A., Vicente, P. G., \& Viedma, A. (2011). Flow field and heat transfer investigation in tubes of heat exchangers with motionless scrapers. Applied Thermal Engineering,31(11-12), 2013-2024.

[2] Sarma, P. K., Subramanyam, T., Kishore, P. S., Rao, V. D., \& Kakac, S. (2003). Laminar convective heat transfer with twisted tape inserts in a tube. International Journal of Thermal Sciences, 42(9), 821-828.

[3] Rainieri, S., \& Pagliarini, G. (2002). Convective heat transfer to temperature dependent property fluids in the entry region of corrugated tubes. International Journal of Heat and Mass Transfer, 45(22), 4525-4536.

[4] Patil, A. G. (2000). Laminar flow heat transfer and pressure drop characteristics of power-law fluids inside tubes with varying width twisted tape inserts. Journal of Heat Transfer, 122(1), 143-149.

[5] Laohalertdecha, S., \& Wongwises, S. (2011). Condensation heat transfer and flow characteristics of R-134a flowing through corrugated tubes. International Journal of Heat and Mass Transfer, 54(11-12), 2673-2682.

[6] Agarwal, S. K., \& Rao, M. R. (1996). Heat transfer augmentation for the flow of a viscous liquid in circular tubes using twisted tape inserts. International Journal of Heat and Mass Transfer, 39(17), 3547-3557.

[7] Eiamsa-Ard, S., \& Promvonge, P. (2010). Performance assessment in a heat exchanger tube with alternate clockwise and counter-clockwise twisted-tape inserts. International Journal of Heat and Mass Transfer, 53(7-8), 1364-1372.

[8] Deb, D., \& Poudel, S. (2017). Investigation of Heat Transfer Enhancement in Laminar Flow through Circular Tube by using Combined Wire Coil and Wavy Strip with Central Clearance. IJEAT, 6, 158-164.

[9] Eiamsa-Ard, S., Rattanawong, S., \& Promvonge, P. (2009). Turbulent convection in round tube equipped with propeller type swirl generators. International Communications in Heat and Mass Transfer, 36(4), 357-364.
[10] Chamkha, A. J. (2002). Hydromagnetic combined convection flow in a vertical lid-driven cavity with internal heat generation or absorption. Numerical Heat Transfer: Part A: Applications, 41(5), 529-546.

[11] Cheng, T. S., \& Liu, W. H. (2010). Effect of temperature gradient orientation on the characteristics of mixed convection flow in a lid-driven square cavity. Computers \& Fluids, 39(6), 965-978.

[12] Khanafer, K., \& Aithal, S. M. (2013). Laminar mixed convection flow and heat transfer characteristics in a lid driven cavity with a circular cylinder. International Journal of Heat and Mass Transfer, 66, 200-209.

[13] Chatterjee, D., Halder, P., Mondal, S., \& Bhattacharjee, S. (2013). Magnetoconvective transport in a vertical lid-driven cavity including a heat conducting square cylinder with Joule heating. Numerical Heat Transfer, Part A: Applications, 64(12), 1050-1071.

[14] Ray, S., \& Chatterjee, D. (2014). MHD mixed convection in a lid-driven cavity including heat conducting circular solid object and corner heaters with Joule heating. International Communications in Heat and Mass Transfer, 57, 200-207.

[15] Al-Salem, K., Öztop, H. F., Pop, I., \& Varol, Y. (2012). Effects of moving lid direction on MHD mixed convection in a linearly heated cavity. International Journal of Heat and Mass Transfer, 55(4), 1103-1112.

[16] Ismael, M. A., Pop, I., \& Chamkha, A. J. (2014). Mixed convection in a lid-driven square cavity with partial slip. International Journal of Thermal Sciences, 82, 47-61.

[17] Dipan Deb, Sajag Poudel, Abhishek Chakrabarti, 2017, Numerical Simulation of Hydromagnetic Convection in a Lid-driven Cavity Containing a Heat Conducting Elliptical Obstacle with Joule Heating, INTERNATIONAL JOURNAL OF ENGINEERING RESEARCH \& TECHNOLOGY (IJERT) Volume 06, Issue 08 (August 2017), http://dx.doi.org/10.17577/IJERTV6IS080055

[18] Dipan Deb, Sajag Poudel, Abhishek Chakrabarti, 2017, Numerical Simulation of Hydromagnetic Convection in a Lid-driven Cavity Containing a Heat Conducting Inclined Elliptical Obstacle with Joule Heating, INTERNATIONAL JOURNAL OF ENGINEERING RESEARCH \& TECHNOLOGY (IJERT) Volume 06, Issue 10 (October 2017), http://dx.doi.org/10.17577/IJERTV6IS100090

[19] Chu, K. H., Enright, R., \& Wang, E. N. (2012). Structured surfaces for enhanced pool boiling heat transfer. Applied Physics Letters, 100(24), 241603.

[20] Chen, R., Lu, M. C., Srinivasan, V., Wang, Z., Cho, H. H., \& Majumdar, A. (2009). Nanowires for enhanced boiling heat transfer. Nano letters, 9(2), 548-553.

[21] Zou, A., S. Poudel, S. P. Raut, and S. C. Maroo. "Pool Boiling Coupled with Nanoscale Evaporation Using Buried Nanochannels." Langmuir: the ACS journal of surfaces and colloids 35, no. 39 (2019): 12689.

[22] Poudel, S., Zou, A., \& Maroo, S. C. (2019). Wicking in Cross-Connected Buried Nanochannels. The Journal of Physical Chemistry C, 123(38), 23529-23534.

[23] Zou, A., \& Maroo, S. C. (2013). Critical height of micro/nano structures for pool boiling heat transfer enhancement. Applied Physics Letters, 103(22), 221602.

[24] Yao, Z., Lu, Y. W., \& Kandlikar, S. G. (2012). Fabrication of nanowires on orthogonal surfaces of microchannels and their effect on pool boiling. Journal of Micromechanics and Microengineering, 22(11), 115005.

[25] Plawsky, J. L., Fedorov, A. G., Garimella, S. V., Ma, H. B., Maroo, S. C., Chen, L., \& Nam, Y. (2014). Nano-and microstructures for thin-film evaporation-A review. Nanoscale and microscale thermophysical engineering, 18(3), 251-269.

Ranjan Kumar is a Mechanical Engineering student currently working in the projects related to thermos-fluids. His interest lies in the field of heat transfer, energy conversion and thermodynamics. So far he has one journal article and appeared in several conferences of related field.

Shreya Agarwal is a postgraduate student of Mechanical Engineering in a university in India. She graduated from BIT and right now studying and doing research in the field of thermal sciences and manufacturing. She has a few journal papers and conferences papers till date. 